\title{
La narrativa chilena y el riesgo de la insignificancia
}

\section{The Chilean Narrative and the Risk of Insignificance}

\author{
Patricia Espinosa $\mathrm{H}$. \\ Pontificia Universidad Católica de Chile \\ pcespinosa@gmail.com
}

\section{Resumen}

El mayor capital de nuestra narrativa, enclaustrada bajo un techo de acero, es el yo, que ha dejado a oscuras a la otredad, el colectivo. Esta narrativa se adscribe rigurosamente al realismo capitalista, centrada en un yo, esencialista, deshistorizada, emotiva, privatizada en cuanto a la preocupación por él/la sujeto/a protagonista y su entorno afectivo; además, sin expectativas de futuro, en constante trayecto hacia el pasado infantil o adolescencial. La definición del momento histórico por el que actualmente atraviesa la literatura chilena, es el de un lento pero decidido declive hacia la insignificancia. No está a punto de desaparecer, por el contrario, se está publicando mucho, incluso en pandemia. Tampoco quiero decir que en este siglo no se hayan publicado obras valiosas. Las hay y en buen número. Más bien se trata del corrimiento de lo literario en su conjunto hacia una zona de insignificancia cultural. Camino a convertirse en un nicho de consumo definido por un rango decididamente decreciente, la literatura parece estar rebelándose poco frente a este dramático hecho.

Palabras clave: Narrativa chilena, posdictadura, literatura y crisis, neoliberalismo literario, literatura y mercancía.

\section{Abstract}

The greatest value of our narrative, cloistered as it is under a roof of steel, is the self, which has left otherness and the collective in the dark. This narrative is rigorously ascribed to capitalist realism, centered on an essentialist, dehistoricized, emotional, and privatized self in terms of the narrative's concern by his/her protagonist subject and his/her affective environment. It is also a narrative without expectations for the future, a constant journey towards a childish or adolescent past. The definition of the historical moment that Chilean literature is currently going through is that of a slow but determined decline towards insignificance. It is not about to disappear; on the contrary, it is being published abundantly, even in a pandemic. I do not mean that valuable works have not been published in this century. There are and in good number. Rather, we are witnessing a shift of the literary as a whole into an area of cultural insignificance; it is a narrative that is on the way to becoming a consumer niche defined by a decidedly declining rank. Literature seems not to be rebelling against this dramatic fact.

Keywords: Chilean narrative, post-dictatorship, literature and crisis, literary neoliberalism, literature and commodities. 
La definición del momento histórico por el que actualmente atraviesa la literatura, por lo menos en Chile, es el de un lento pero decidido declive hacia la insignificancia. No está a punto de desaparecer, ni nada por el estilo, por el contrario, se está publicando mucho, incluso en pandemia. Tampoco quiero decir que en este siglo no se hayan publicado obras valiosas. Las hay y en buen número. Más bien se trata del corrimiento de lo literario en su conjunto hacia una zona de insignificancia cultural. Camino a convertirse en un nicho de consumo definido por un rango decididamente decreciente, la literatura parece estar rebelándose poco frente a este dramático hecho. En la última década, solo las escrituras de mujeres han tenido la fuerza comunitaria suficiente para cuestionar el devenir insignificancia de lo literario, devolviéndole a la literatura ese carácter de interpelación a los poderes sin el cual la literatura se convierte solo en una mercancía más.

Reitero que cuando la literatura deja de ser un territorio de disputa con las lógicas dominantes, cae en la insignificancia. Esta insignificancia a pesar del aumento en la cantidad de publicaciones, la emergencia de un fuerte movimiento de editoriales autogestionadas o la presencia de autoras y autores nacionales en campañas de difusión internacional. Más allá del entusiasmo que provocan estos fenómenos, la insignificancia se acrecienta. Nuestra narrativa ya no intenta parecer republicana ni derrocar una dictadura, sino que se ha vuelto ensimismada, agotada, anulada en sus marcas territoriales, sometida a la canonización del mercado y los medios de comunicación.

Durante la dictadura, la narrativa transitó por la alegoría y el realismo orientados a representar el genocidio y sus efectos. En este sentido, podría hablar de una narrativa comprometida con denunciar y derrotar el proyecto autoritario. Con la recuperación de la democracia surgió con ímpetu una voluntad de renovación. Se habló de una suerte de refundación nacional, de nuevos tiempos y, por supuesto, de un proceso que debía ser acompañado por una "nueva narrativa", que terminó siendo un fenómeno editorial ligado al mercado. Dejar atrás los lastres y abrirse al mundo mostrando un rostro renovado, globalizarse aceleradamente para poder participar en el mercado literario internacional. Chile y su trauma de pequeña aldea, alejada de los centros neurálgicos, dio a luz a una generación, ligada a la editorial Planeta, denominada Nueva Narrativa, conformada mayoritariamente por escritores (hombres). Esta generación buscó su internacionalización, adoptando temáticas y lenguajes deprendidos de cualquier color local. Los procesos internos comenzaban a ser lo dominante. Como suele ocurrir, lo más interesante se fue incubando en los bordes de las estrategias comerciales. Un pequeño grupo de autoras y autores siguieron un camino a contrapelo: Diamela Eltit, Guadalupe Santa Cruz y Roberto Bolaño, entre otras/os. Sus escrituras demuestran un compromiso férreo por representar la crisis que la posdictadura encubría en sus discursos triunfalistas. Estas escrituras, además, exceden la crisis psicológica de sus personajes y se encaminan a politizar la escritura. Me refiero con esto a la preocupación por torcer la hegemonía estética del género novela, desmontando la forma y, por supuesto, desarrollando problemáticas ligadas a Latinoamérica y el poder. 
Las escritoras y escritores recién mencionados, a los cuales puedo inscribir dentro de la estética de la crisis del poder, se niegan a proponer utopías y esa es su gran diferencia respecto a las narrativas de la dictadura. Pero fueron los menos. La posdictadura fue hábil en generar como mayor incentivo para las/os escritoras/es la difusión de sus obras fuera del país, la valorización de los libros a partir de las ventas $y$, por sobre todo, la subordinación de la escritura a la figura del autor/a. Esto significa que el relieve de la biografía y la posición de quien escribe ocupan un sitio preferencial dentro del ámbito de los medios de comunicación y ferias del libro. Como nunca antes en la historia del país, ser escritor/a pasó por la visibilidad de la figura autor/a en lo público desprendida del valor estético de la obra.

La transformación de la figura autoral ha sido un camino sin retorno. Hoy más que nunca, debido a las redes sociales y al peso de los medios de comunicación, ser escritor/a es tener una figuración pública. "La lógica del capitalismo, por su parte, fuerza la privatización de las obras: todo libro tiene autor", nos dice Vanina Papalini, agregando que desde mediados del siglo xx: "el libro adquiere un nuevo valor distintivo: el de la escritura, que se vuelve en sí misma un dato de cultura más allá de su calidad" (76). Esto es una parte fundamental del proceso de afirmación del producto creativo como un bien de consumo, es decir, que debe estar ligado a un creador o creadora como producto de su genialidad, de su constancia en el trabajo y de su esfuerzo por llegar a ser conocido o conocida. Para que ese proceso sea exitoso se requiere además la instalación de un sujeto o sujeta deshistorizado/a: un/a escritor/a, carente de pensamiento crítico, cuya producción literaria hace eco de esta vaciedad. La narrativa nacional de posdictadura se ciñe a una base esencialista-capitalista, donde la figura autor/a se encuentra en permanente proceso de legitimación no por su producción literaria, sino por el lugar que ocupa en el campo cultural. Los medios de prensa, las redes sociales, los eventos literarios, incluso la residencia fuera del país, tal como la elite chilena de principios de siglo, conforman estados de situación donde la biografía y la opinión contingente reemplazan la producción de obra.

Recuerdo acá a Ricardo Forster cuando nos habla de un presente hegemonizado por un solipsismo recubierto de una fantasía de libertad nacida desde sí mismo (17), y a Agustín Rodríguez, siguiendo a Forster, señalando: "la subjetivación del sistema actual se centra en la eliminación de barreras institucionales históricas para convertir a cada individuo en un gestor de su propia vida, responsable de administrar su capital humano, avanzando en un gigantesco mecanismo de desocialización que reduce a los individuos a una autoreferencialidad inversora de su propio capital, consumidores y meros competidores bajo los imperativos del mercado" (315). La posición de privilegio que posee la figura autor/a se debe a una jerarquización de base simbólica y mercantil que prioriza la relación autor/a-texto de acuerdo a la lógica del valor de cambio que rige el circuito del mercado. Ser escritor/a es una etiqueta que se sostiene, insisto, más por la figura biográfica que por la obra literaria. 
Esto ha dado como resultado un campo literario diezmado, empobrecido de voz, discurso y compromiso. Interpreto este fenómeno como la internalización de una hegemonía orientada a anular el pensamiento crítico y a convertir el nexo entre escritoras y escritores con las lectoras y lectores en una relación productor-cliente. Ello explica el fenómeno de cientos de escritores y escritoras de "un" libro, y múltiples editoriales y microeditoriales con catálogos que son simplemente el reflejo del ofrecimiento de un "servicio editorial" consistente en acercar al productor a sus posibles clientes. Así, creadores/creadoras y editoriales entran en la categoría de pequeños emprendimientos que buscan replicar el éxito de las grandes empresas que copan el mercado.

Pero el problema no está dado por la presencia de múltiples nuevos actores en la disputa de un lugar en el mercado. Incluso esa variedad claramente es positiva, beneficiosa. El problema radica en el tipo de relación estándar que se establece entre productor y cliente, la cual requiere del respeto de una serie de protocolos que no se deben incumplir.

Durante la dictadura se demonizó la colectividad. Todo grupo de individuos era considerado parte de una trama conspirativa antidictadura que había que eliminar. Aunque de manera menos brutal, pero no menos efectiva, los nuevos gobiernos democráticos supieron mantener esa lógica de exclusión de lo colectivo. La última década del siglo xx y la primera del actual vieron cómo el valor de lo colectivo se devaluaba aceleradamente. Sindicatos, asociaciones gremiales, barriales e incluso las barras bravas del fútbol fueron sometidas a una estigmatización creciente. Esto implicó un énfasis en la individualidad, tanto en términos sociales como en el campo de la cultura, compuesto de subjetividades blandas, vaciadas de pensamiento crítico, incapaces de actuar o pasivas ante el abuso del poder, la desigualdad y la corrupción. Para la posdictadura la única comunidad posible era y es la de los consumidores. Según Enrique Díez:

El capitalismo avanzado es esencialmente destructor de la dimensión colectiva de la existencia. Se asiste a una individualización radical que hace que todas las formas de crisis sociales sean percibidas como crisis individuales, todas las desigualdades sean achacadas a una responsabilidad individual: "hemos vivido por encima de nuestras posibilidades", que convierten a las víctimas en culpables. Hay toda una maquinaria que transforma las causas exteriores en responsabilidades individuales y los problemas vinculados al sistema en fracasos personales (44).

Para luego agregar:

El reverso del discurso de la "realización de sí" y del "éxito en la vida", supone una estigmatización de los "fallidos", de la gente infeliz, o sea, incapaz de acceder a la norma social de la prosperidad. El fracaso social es considerado como una patología. El sujeto neoliberal debe ser previsor en todos los dominios (seguros de todo tipo), debe operar en todo como si se tratara de inversiones (en un "capital educación", en un capital salud, en un "capital vejez"). Ante este 
desgaste provocado por la elección permanente, el remedio más extendido es un dopaje generalizado (46).

El/la sujeto/sujeta despojado/a de la colectividad se enfrenta al individualismo y la crisis que lleva a asumir la derrota como personal y no social, no gubernamental, no estatal o del sistema. El/la sujeto/sujeta excéntrico/a a esta lógica, como señala Díez, poseería la condición de fallido, fracasado. Es este rasgo el que precisamente se hace parte de toda la narrativa posdictadura: el sujeto o la sujeta resulta derrotado/a por un orden innominado que lo margina y resta cualquier opción de pensar su existencia más allá de un presente continuo.

Inscribo en este preciso lugar del ensayo una cita que convoca capitalismo y literatura que me permitirá ingresar a la discusión en torno a la consolidación de la estética de la narrativa capitalista en posdictadura. De acuerdo a Terry Eagleton, "la sociedad capitalista se caracteriza por encima de todo por la presencia en el escenario histórico de un nuevo tipo de protagonista, las masas" (112). Las masas son un vacío en nuestra narrativa, hay que remontarse a la primera mitad del siglo pasado para registrar su presencia. En su reemplazo lo que hay, y con fuerza a partir de la posdictadura, es el culto al personaje, al individuo. Cómo se relacionan ambos fenómenos, bueno, simplemente porque la narrativa ofrece sin muchas complicaciones un espacio de individuación, de aislamiento, con lo cual se garantiza dejar fuera las tensiones implícitas en lo social. La masa está compuesta por individuos aislados, no por sujetas y sujetos, y es ese individuo aislado es el que está siendo narrado/a. Cuando Eagleton se refiere a la novela burguesa condicionada por la hegemonía capitalista, señala que se pide de ellos (los escritores) que sean "metafísicos en la teoría y pragmáticos en la práctica" (113). No puede haber enunciado más preciso para calificar nuestra narrativa de posdictadura: metafísica en las ideas y pragmática en la escritura, a lo cual agrego, conservadora en la forma. En eso se basa el respeto al protocolo estandarizado que mantiene la relación productor-cliente. Una escritura que se ciñe al idealismo/esencialismo como hegemonía estético-literaria. La literatura, por tanto, surge como expresión emocional del yo, esto implica la amplia cantidad de obras donde se impone la subjetividad y las intimidades en crisis. Esto significa subjetividades tensionadas por un conflicto interior, insertas en un "paisaje" más que en un contexto. Una novela puede acontecer en Santiago o Valparaíso, sin embargo, el espacio opera como un escenario neutro, carente de una mirada cuestionadora. En definitiva, obras realistas sí, pero de un realismo de la intimidad y, aunque suene casi una contradicción decirlo, un realismo sin sociedad. Esto deriva en una disociación entre la obra literaria y los procesos históricos. Escrituras, por tanto, des-situadas, fuera del contexto en que surgen, donde la historia del país o de una coyuntura histórica poco y nada importa respecto a los vaivenes de una intimidad en crisis.

Lo anterior implica la producción de textos literarios deslocalizados, que no admiten en su factura ni en su discurso vinculación alguna con un fuera del texto. La narrativa, de tal modo, se aleja definitivamente de cualquier exterioridad. Apegándose con ello 
a la inmanencia y la autonomía. Las obras resultantes se remiten a un espacio interior que aprisiona, un espacio autónomo, que poco y nada tiene que ver con el fuera del texto. Coincido con Nelly Richard en su definición de lo político en el arte como aquello que "rechaza la correspondencia entre forma y contenido para interrogar, más bien, las operaciones de signos y las técnicas de representación que median entre lo artístico y lo social", para luego agregar: "Lo político en el arte nombraría una fuerza crítica de interpelación y desacomodo de la imagen, de conflictuación ideológico-cultural de la forma-mercancía de la globalización mediática: una globalización que busca seducirnos con las pautas visuales del consumo como única escenografía de la mirada”. Para Richard, lo político se opone a la correspondencia entre contenido y forma, optando por las operaciones de representación entre el exterior y el interior de la obra de arte. Estas operaciones pondrían en juego la visibilización del conflicto ideológico que ve la obra de arte como mercancía global, desasida de diferencialidades. En tal sentido, la narrativa neoliberalizada monta contenido y forma, sin someter a conflicto ambos niveles ni menos establecer vasos comunicantes entre el texto y el fuera del texto. La función representacional de la narrativa queda así anulada, convertida en un signo vacío.

Un aspecto que merece también observación en la narrativa chilena posdictadura es la presencia de la estética posmoderna, manifiesta en la caída de las ideologías y la obsolescencia de las utopías; dando lugar a escrituras pegadas a una suerte de presente continuo, doméstico, donde se advierte desencanto y conformismo. Por tanto, su mayor conflicto se manifestará en la búsqueda de afectos transitorios. Estas escrituras confirman personajes atomizados en mundos autónomos, donde opera una episteme patriarcal. La mayor parte de la narrativa publicada en Chile es producida por autor varón. Se trata de textos protagonizados, además, por varones, heterosexuales, donde la mujer aparece como una figura estereotipada. Minoritariamente, se publican novelas sobre disidencias sexuales, donde se impone también un modelo de género apegado al esencialismo.

Las narrativas de autoría mujer comienzan a proliferar en nuestro país a partir del año 2000. Cabe agregar a este fenómeno el surgimiento de microeditoriales gestionadas por mujeres que abren colecciones dedicadas a escrituras de mujeres y la consolidación de una discursividad crítica feminista, expresada tanto en el mundo académico como, principalmente, en organizaciones sociales. Pese a todo, la narrativa de mujeres ocupa un lugar menor dentro del caudal de publicaciones nacionales y no toda narrativa escrita por una mujer es feminista. Es preciso distinguir, respecto a esto último, entre escrituras en proceso de emancipación y escrituras patriarcalizadas. Estas últimas implican la reproducción de la lógica masculinizante, por tanto no constituyen un aporte a la política de género, ya que más bien reproducen el ideal masculino de la mujer. Heterosexual, sensitiva, ligada al espacio doméstico, silenciosa, en permanente estado de aprobación ante la masculinidad, ocupando una voz y un lugar asignado a partir de su condición subalterna. Una de las razones para esto es la condición burguesa de nuestras escritoras y su formación académica, dos caracte- 
rísticas que suelen ir unificadas y que permean variedades de escrituras donde, entre otras cosas, no aparece la mujer del mundo popular, la mujer perteneciente al pueblo originario, la mujer inmigrante ni la mujer trans.

Pues bien, la narrativa de mujeres experimenta un proceso de retardo en lo que respecta a las políticas de género y localización. Nuestro proceso de consolidación de una narrativa de la emancipación es lento, desfasado incluso respecto a otros países latinoamericanos como Argentina o México. Es necesario agregar que las producciones de mujeres son sometidas a un constante proceso de invisibilización desde el mercado editorial y desde el lugar de la crítica. Estas prácticas operan de dos formas: una, de manera brutal, es decir, por medio de la exclusión abierta, evidente; otra forma de invisibilizar las escrituras de mujeres es leer a partir de la denominación "escritura femenina”. Esto significa identificar en la escritura de mujeres las convenciones de configuración impuestas desde lo patriarcal: sensibilidad, afectividad, sentimentalismo, pasividad, virginidad, maternalismo, privilegio del cuerpo por sobre el logos. Pese a ello, la literatura de mujeres se ha convertido en una práctica política que permite identificar el modo en que las propias mujeres se autoconstruyen e identifican ante la lógica patriarcal.

En el último año, el contexto político nacional ha cambiado de manera radical. El 18 de octubre de 2019 es una fecha que marca el inicio de la Revuelta Social. Tras treinta años de neoliberalismo, la población se vuelca a la calle y clama por un cambio de modelo. Igualdad en el derecho a la salud y educación, así también como una mejora en las pensiones han sido las motivaciones centrales de la movilización ciudadana. La Revuelta Social y la consolidación del movimiento feminista, que había emergido con fuerza en el Mayo Feminista del 2018, conforman un escenario donde es posible advertir la presencia de utopías, un proyecto de futuro y, por sobre todo, la emergencia de la colectividad por sobre el individualismo.

La revuelta ha dejado en evidencia una crisis multisectorial de años, silenciada por los medios de comunicación y el aparato político-partidista. Sin duda nos encontramos ante una crisis social donde se ha impuesto una violencia de Estado que opera transgrediendo derechos humanos, en virtud de paralizar las legítimas demandas de la ciudadanía. Por tanto, no solo nos enfrentamos al ejercicio de una violencia epistémica devenida desde la oficialidad política y los medios de prensa, sino que en simultáneo acontece un ejercicio de violencia material, dirigida a los cuerpos y las cuerpas, asimilable a los tiempos de dictadura. El país vive bajo un permanente estado de excepción, más de un año bajo un conjunto de normativas que ordenan los modos de circulación por la ciudad. Se ha intentado, desde la autoridad, naturalizar los cuerpos heridos, asesinados, enceguecidos, violados, recluidos. En este escenario, una se pregunta qué pasa con las escrituras, específicamente, las ficciones. Históricamente hemos sido educadas y educados en el cliché de la literatura como acto de resistencia, al igual que el ejercicio de la crítica. Sin embargo, hoy la narrativa de ficción se hace a un lado. Y no solo hoy, diría, sino en todo el periodo denominado posdictadura. 
Nuestras literatas y literatos han manifestado en múltiples ocasiones a través de redes sociales, post 18 de octubre de 2019, que se dedicarán a reflexionar. Esto lleva a sospechar que será un largo proceso y que las obras surgirán de acuerdo a tiempos personales. Si bien esta decisión tiene apariencia de razonable, me parece ligada nuevamente a una racionalidad que desea observar los hechos de manera ¿científica?, ¿objetiva?, ¿distanciada? Lo que sí está claro es que la literatura no acompañó este proceso, no fue a buscar lectores, lectoras, lectorxs, no se manchó de contingencia. Opción que confirma, en todo caso, lo señalado antes: la literatura ya no corre pegada a la realidad. Ha tomado caminos disociados, y si vuelven a reunirse literatura e historia, será a través de un proceso de filtración de lo real, templado, desligado de la efervescencia que otorga escribir desde el interior de la crisis. ¿Estarán esperando un momento poscrisis? Sería ingenuo. A menos que alguien siga creyendo que "la alegría ya viene", es decir, esperando que las elites se recompongan y diseñen nuevamente un futuro de estabilidad y prosperidad. Este esperanzador futuro implicaría un tiempo de templanza, quietud, donde se pueda elaborar una escritura desde una subjetividad que no depende de la urgencia histórica ni menos del testimonio desenfrenado.

Muy atrás ha quedado el voluntarismo vanguardista dispuesto a generar una "literatura fundante", expresión que alguna vez utilizó Octavio Paz de la siguiente manera:

[...] la realidad se reconoce en las imaginaciones de los poetas; y los poetas reconocen sus imágenes en la realidad. Nuestros sueños nos esperan a la vuelta de la esquina. Desarraigada y cosmopolita, la literatura hispanoamericana es regreso y búsqueda de una tradición. Al buscarla, la inventa. Pero invención y descubrimiento no son los términos que convienen a sus creaciones más puras. Voluntad de encarnación. Literatura de fundación (284-285).

Visión comentada entusiastamente por Miguel Barnet, quien así dice:

Esa literatura de fundación que postula Paz no sale así, del sombrero de un mago. Es una larga tarea de desarrollo. Una síntesis. Y esa síntesis debe contener la mayor cantidad de elementos puros posibles. Es decir, que debe abarcar tanto el mundo de lo real como el de lo irreal, y todo en función de levantar esa pirámide espiritual que tanta falta le hace a nuestra América (285).

Es cierto que Paz y Barnet apelan a una visión purista de la literatura siempre en búsqueda de un origen, incluso Barnet enfatiza la necesidad de una "pureza" que dará como fruto una espiritualidad americana. Más allá de eso, lejos ha quedado el entusiasmo y la épica, y si eso se puede discutir, lo que es innegable es que la capacidad de riesgo definitivamente se ha perdido. Lo que sí se puede esperar es la reaparición de una posible novela-testimonio, definida por el propio Barnet como "un desentrañamiento de la realidad, tomando los hechos principales, los que más han afectado la sensibilidad de un pueblo y describiéndolos por boca de uno de sus protagonistas más idóneos" (288) para contribuir así a "la memoria colectiva" (294). Narrativa, a 
fin de cuentas, de la crisis, expuesta desde adentro por uno de sus protagonistas, no mero testigo. No estoy de acuerdo con esto último, la idoneidad de la voz narrativa principal no pasa por su condición protagónica, ya que la voz perfectamente puede ser la de un/a testigo. Donde coincido con Barnet es en ligar novela-testimonio con hechos que han sensibilizado al pueblo, que se oriente a representar la crisis.

Una pregunta surgida de los medios de comunicación masivos ha sido: ¿Qué pasará con la literatura posrevuelta? A lo cual podría agregar: ¿qué pasará con la literatura pospandemia? Como lectores y lectoras una posibilidad es releer nuestra narrativa, identificar los indicios de la crisis actual, y quizás confirmar ese maravilloso mito que nos dice que la literatura prefigura la realidad. Otra opción, desde el lugar de las escritoras y escritores es reelaborar la crisis. La literatura, en cualquier caso, se sostiene en la crisis, el conflicto, venga de donde venga y desde siempre. Por tanto, esta veta no haría sino más que reproducir una carga simbólica históricamente adscrita a la ficción narrativa, sin embargo adelgazada en la creación nacional del siglo XxI.

La literatura ya no es el "instrumento adecuado para forjar la identidad" como señalara alguna vez Simón Rodríguez (Rama 13). Desde mi mirada la identidad se ha intercambiado por el concepto de subjetivación. Ya no más una identidad ligada a la pertenencia a la patria, sino una subjetividad que da cuenta, precisamente, del proceso de convertirse en sujeta o sujeto de discurso. No me parece posible que ligar la localización de la subjetividad con la historia sea un mero gesto contenidista. Las obras literarias, aun cuando son una práctica cultural no son, como señalara Ángel Rama, "meros documentos sociológicos" (19). Esto no es una traba a la concepción de una identidad narrativa, como señala Arfuch siguiendo a Ricoeur, para abordar tanto la identidad individual como la colectiva, distanciada del esencialismo, en un intervalo que entraña "la mismidad —el/lo mismo- e ipseidad —el sí mismo/otro- que se despliega" (138). Con esto quiero decir que los procesos de subjetivación narrativos que se basculan hacia la clausura del otro, clausuran a la vez su posible historicidad, de ahí su tendencia metafísica. Por lo tanto están permanentemente en peligro de convertirse en procesos de subjetivación truncados, ya que lo histórico, la experiencia, el devenir en el tiempo real y concreto, que incluye inevitablemente a lo social y a las otras y otros, a lo comunitario, en definitiva, queda si no fuera o, por lo menos, visualizado como detrás de un vidrio empañado donde se mezcla con el propio reflejo, el que termina gobernando la escena.

La condición de sujeta o sujeto que se desvía de la tendencia hegemónica de la narrativa de fines de siglo $\mathrm{xx}$ es la de un territorio donde se cruzan las variables de género, clase, raza, cultura. Su porosidad está en directa relación con una escritura nómade (Braidotti 113). El sujeto textualizado por gran parte de nuestra narrativa de posdictadura se encuentra mayoritariamente ajeno a tales variables. Su escritura, por tanto, no tiene nada de nómade. Todo lo contrario, se encuentra localizada, insisto, pero solo en sí misma. Sometida a una lógica del self-made-man (Valencia 30) donde el autor se asume como un emprendedor o "persona que identifica una oportunidad y organiza los recursos necesarios para ponerla en marcha” (45). Esto implica, como 
he dicho, que la ficción narrativa no acusa resonancias de lo comunitario y que la producción literaria sea concebida al modo microempresarial, como una oportunidad para poner un producto y una biografía en circulación. La escritura, como señala Cortázar en otro contexto histórico, pero igualmente vigente en el presente latinoamericano y, en particular, chileno, es advertida de la siguiente forma:

[...] en el plano del lenguaje sucede algo muy grave en el campo ideológico. No solo en la lucha prerrevolucionaria que se lleva a cabo en tantos terrenos, sino incluso en los casos donde las revoluciones han sido ya conseguidas, el lenguaje se queda atrás, el lenguaje no está a la altura de una revolución, el lenguaje es adocenado. Seguimos escuchando discursos con la misma retórica y las mismas fórmulas que son precisamente las del sistema que queremos destruir; seguimos escuchando frases donde un cierto adjetivo se pega fatalmente a un cierto sustantivo, sin que la persona que lo emplea haya reflexionado jamás que, al idioma, hay que renovarlo de la misma manera que hay que renovar la política y hay que cambiar la economía, porque el idioma es nuestro vehículo interno de pensamiento, y si pensamos con las palabras, sabemos muy bien también que las palabras contribuyen al pensamiento. Un idioma esclerosado, un idioma lleno de prejuicios, tabúes y viejas fórmulas, está trabando nuestra posibilidad de avance hacia ese esquema del hombre futuro por el cual luchamos (432).

El "lenguaje se queda atrás" o "no está a la altura" de la lucha social señala Cortázar. La escritura literaria, por ende, queda desfasada de la narrativa comunitaria. No hay experimentación, movilización de retóricas y géneros. En este nuevo siglo los géneros literarios respiran perfectamente en sus encajonados límites históricos. Belén Gopegui, en esta misma línea, señala: "En 1970, Rodolfo Walsh decía a Ricardo Piglia durante una entrevista: 'Nuestras clases dominantes han procurado siempre que los trabajadores no tengan historia, no tengan doctrina, no tengan héroes y mártires. Cada lucha debe empezar de nuevo, separada de las luchas anteriores: la experiencia colectiva se pierde, las lecciones se olvidan. La historia parece así como propiedad privada cuyos dueños son los dueños de todas las otras cosas"' (s. p). La hegemonía neoliberal apela a la deslocalización y deshistorización de la colectividad. Por lo mismo, es fundamental la presencia de la memoria a nivel cultural y literario.

Sin embargo, ahí se abre otra zona que también ha corrido el riesgo de la colonización neoliberal. En cuanto a narrativa de posdictadura, la invocación a la memoria tiene lugar; sin embargo, se trata de una memoria ligada a un/a sujeto/a y su familia, una vez más desasido/a de la historia del país. La memoria es acotada y privatizada, volcada hacia la interioridad de personajes orientados a conformar un presente que visualizan al modo de un puzle al cual le faltan piezas. Esta necesidad de completar la figura no necesariamente implica ir al origen o descubrir la causa de la falta de expectativas del presente, sino única y exclusivamente se remite a un despliegue temporal, esencialista, sin sentido material para el hoy ni el mañana. 
En medio de este panorama, advierto la emergencia de escrituras que, aunque en muchos casos conviven con la deshistorización, van a contrapelo. Me refiero con esto a producciones narrativas de mujeres, orientadas a identificar el modo en que se autoconstruyen y confrontan al poder masculino. En estas primeras dos décadas del siglo XXI, puede contarse la publicación de más de quinientos libros de autoría de mujeres, una cantidad importante, aunque menor a la cantidad de publicaciones de autoría masculina. El incremento de escrituras de mujeres, en el género narrativo, no ha hecho variar significativamente la posición de marginalidad de sus obras. Respecto a esto último, es necesario establecer que tanto en la crítica literaria académica como en aquella que se publica en medios de comunicación masivos, a la cual denomino crítica transacadémica, la siguiente salvedad: si bien en las universidades se investiga la producción de mujeres, es en una proporción menor. Recordemos que ha sido una constante este último tiempo que nuestras estudiantes soliciten la apertura del canon bibliográfico.

Advierto en estas escrituras de mujeres, en el siglo xxI, una escritura que subvierte, rechaza y polemiza con los modelos patriarcales sobre la mujer. Esta literatura busca la emancipación en todos sus ámbitos y la visibilización de su diferencia. La figura de la mujer, en este tipo de literatura, es la de un signo que se va construyendo en el itinerario textual o devenir literario, en tensión con las fórmulas de definición de mujer elaboradas desde los patriarcados. Respecto a la diversidad de patriarcados, identifico una hegemonía país, pero también una diversidad de microprácticas patriarcales que se dan en el día a día, espacios comunes, pero también a nivel de campo cultural.

Desde mi perspectiva, la narrativa de mujeres manifiesta una política del desacuerdo a la violencia epistémica patriarcal mediante la modulación de utopías, insubordinación al patriarcado, privilegio de la memoria y autoconfiguración de la sujeta. Las narradoras exponen los efectos de la hegemonía del patriarcado o de los patriarcados neoliberales, como señala la activista boliviana María Galindo, y sus modos de construcción de la mujer (25-27). Estamos frente a una insistencia pertinaz de desacato a los patrones impuestos por la dominancia cultural. La insubordinación se constituye como una "amenaza a todo el sistema jerárquico masculino, es decir, se considera un "acto de insubordinación e insolencia" (Eisler 126).

Las narrativas de mujeres, de tal modo, exponen una estética de la opacidad, de significados oscurecidos, aquellos, que en última instancia, gran parte de la estética posmoderna o neoliberal rechaza. Las narrativas de mujeres son un lugar de memoria: del dolor, del trauma, de la fisura, de la sobrevivencia. Así nos encontramos ante sujetas que intentan recuperar el sentido o parte de este. De acuerdo a Elizabeth Jelin: "El acontecimiento o el momento cobra entonces una vigencia asociada a emociones, y afectos que impulsan una búsqueda de sentido. El acontecimiento rememorado o 'memorable' será expresado en una forma narrativa, convirtiéndose en la manera en que el sujeto construye un sentido del pasado, una memoria que se expresa en un relato comunicable" (27). Reconstruir el pasado permite reelaborar el presente, asimismo, el presente permite la reconstrucción del pasado. Según Jelin, la experiencia de memoria 
se realiza en un "pasado presente" (27), a lo cual podemos agregar, de acuerdo a las novelas nacionales de autoría mujer, que también se realizan en un "presente pasado". Dando lugar, así, a una interacción constante entre pasado y presente, la cual no se agota en la consideración del pasado como origen del presente.

La narrativa chilena de mujeres ${ }^{1}$ afirma la diferencialidad de género, privilegiando el protagonismo de un femenino diverso al masculino. Me parece importante destacar que esa diferencia se orienta a exponer a una sujeta en permanente proceso de construcción. De tal manera, memoria, género y cuerpo podrían ser consideradas como instancias fundantes en la construcción de la sujeta o, en otras palabras, de la no-sujeta, sobre todo si consideramos que se trata de construir una mujer que vaya más allá de las definiciones patriarcales. Las mujeres que habitan estas narrativas se encuentran insertas en procesos de permanente errancia, difiriendo definir la sujeta que quisieran ser. Esta errancia no implica la conformación de un estado de sujeta, sin embargo sí implica un proceso de configuración de subjetivación política, es decir, de consciencia de su lugar menor y discursividad de resistencia.

En particular en el nuevo siglo, la narrativa de mujeres chilenas instala una politicidad disidente a las matrices ideológicas patriarcales, el mercado, la crítica y el feminismo neoliberalizado impuesto desde el Estado. Esta narrativa tiene como eje la representación de la mujer desde la diferencia; es así como lo masculino se materializa en figuras de violencia, autoridad, abandono y debilidad, mientras que lo femenino se configura como una entidad en proceso de subjetivación. Mediante microtácticas de insubordinación, las protagonistas se visibilizan como una entidad en proceso, que revierte el tránsito pasado-presente desde una memoria fragmentada, que las lleva a recuperar el pasado a partir de retazos, asumiendo —además- el cuerpo como territorio marcado por la violencia devenida de la figura masculina. Finalmente, cabe señalar que la mujer es asumida desde una diferencia de género ligada a la sobrevivencia y las utopías, insubordinada ante todo aquello que castre su sobrevivencia en un contexto posépico y posmetafísico.

Los personajes que circulan por estas narrativas se encuentran en un proceso constante de itinerancia o de subjetivación política que pone en crisis la condición de sujeta. Sin embargo, aun cuando la sujeta esté en proceso de construcción, implica acciones afirmativas medianamente estables o, por lo menos, lo suficientemente estables como para sostener el acto de insubordinación. Este itinerario o proceso de subjetivación se puede concebir desde una mirada no lineal y anticausalista; es decir, asumiendo la diseminación de enunciados y acciones experimentados por los personajes.

Tal como señala Castany, vivimos en la era de la globalización que ha provocado la erosión del estado-nación (36). Según este autor, "la literatura parece haberse

1 Destaco el trabajo de años realizado por Diamela Eltit, Cynthia Rimsky, Nona Fernández, Lina Meruane, Alejandra Costamagna, Andrea Jeftanovic, Eugenia Prado; así también el de recientes narradoras como: Romina Reyes, Alia Trabucco, Sara Bertrand, Daniela Catrileo, Mónica Drouilly. 
adelantado a las ciencias sociales en la búsqueda, consciente o inconsciente, de descripciones identitarias más adecuadas a la irreductible complejidad del mundo y las personas que lo habitan" (36-37). Esto significaría que las/os escritoras/es, producen escrituras en función de ir más allá de su lugar de origen y volverse globales. Esto es, en definitiva, lo que Bernat denomina posnacionalismo. Concuerdo con lo planteado, a lo cual agregaría, en un tono menos celebratorio, que estas derivas se producen por influencia del mercado. El posnacionalismo ha dado como resultado una narrativa rendida a una estética neoliberal. Centrada en un yo, esencialista, insisto, deshistorizada, emotiva, privatizada en cuanto a la preocupación por él/la sujeto/a protagonista y su familia o entorno afectivo cercano; además, sin expectativas de futuro, en constante trayecto hacia el pasado infantil o adolescencial. Estas características forman parte de lo que puedo llamar realismo capitalista. En un sentido más específico que el otorgado por Mark Fischer en su libro Realismo Capitalista: ¿No hay alternativa?, volumen ligado al cine y la música primermundista, donde plantea la opción de renovación política-estética en este nuevo siglo, sin caer en la nostalgia ni la desazón respecto al futuro, abriendo una pequeña ventana a la instauración de un discurso donde sí habría alternativa al capitalismo (21-34).

El mayor capital de nuestra narrativa-domo, enclaustrada bajo un techo de acero, es el yo, que ha dejado a oscuras a la otredad, el colectivo. Esta narrativa se adscribe rigurosamente al realismo capitalista, por las razones mencionadas en el párrafo anterior. Sin embargo, hacia el cierre de estas reflexiones, quiero tomar una vía menos decadentista y sospechar, o imaginar si se quiere, que el neoliberalismo ha sido puesto en crisis, ha demostrado fragilidad y, por sobre todo, está siendo rechazado mayoritariamente en nuestro país. No caeré en discursos de refundación nacional, me parece absurdo. He intentado a través de este ensayo, un género históricamente detentado por el patriarcado, elaborar algunas ideas en proceso. Creo firmemente en la concepción del arte y, por supuesto, de la literatura adherida a sus procesos históricos. Estamos en medio de la mayor crisis de la posdictadura y no me cabe duda de que nuestra narrativa encontrará las vías que la lleven a situarse y asumir una posición política sobre la catástrofe sin retorno en la que nos encontramos.

\section{Referencias}

Arfuch, Leonor. "El espacio teórico de la narrativa: un desafío ético y político". Utopía y Praxis Latinoamericana. Revista Internacional de Filosofía Iberoamericana y Teoría Social, año 13, n. ${ }^{\circ}$ 42, (julio-septiembre 2008), pp. 131-140.

Barnet, Miguel. "La novela-testimonio. Socio-literatura". Testimonio y Literatura. Eds. Hernán Vidal y René Jara. Mineápolis, Society for the Study of Contemporary Hispanic and Lusophone Revolutionary Literatures, 1986.

Braidotti, Rosi. Sujetos nómades. Buenos Aires, Paidós, 2000. 
Castany Prado, Bernat. Literatura posnacional. Murcia, Servicios de publicaciones de la Universidad de Murcia, 2007.

Cortázar, Julio. "El lenguaje no está a la altura de una revolución, el lenguaje es adocenado". Cuadernos de literatura, vol. xx, n. ${ }^{\circ} 39$, enero-junio 2016, pp. 428-446.

Díez, Enrique Javier. “La construcción educativa del nuevo sujeto neoliberal”. El viejo topo, n. ${ }^{\circ} 320,2014$, pp. 38-47.

Eagleton, Terry. "Capitalismo y forma”. Disponible en: https://newleftreview.es/ issues/14/articles/terry-eagleton-capitalismo-y-forma.pdf (Revisado 9 de diciembre de 2020).

Eisler, Riane. Placer sagrado. Sexo, mitos y política del cuerpo. Santiago, Cuatro Vientos, 1998.

Fisher, Mark. Realismo capitalista ¿No hay alternativa? Buenos Aires, Caja Negra, 2016.

Forster, Ricardo. La sociedad invernadero. El neoliberalismo: entre las paradojas de la libertad, la fábrica de subjetividad, el neofascismo y la digilitalización del mundo. Buenos Aires, Akal, 2019.

Galindo, María. No se puede descolonizar sin despatriarcalizar. Santa Cruz, Mujeres Creando, 2014.

Gopegui, Belén. "Literatura y política bajo el capitalismo". Disponible en: https:// rebelion.org/literatura-y-politica-bajo-el-capitalismo/ (Revisado 10 de noviembre de 2020).

Jelin, Elizabeth. Los trabajos de la memoria. Madrid, Siglo xxi, 2001.

Papalini, Vanina. "Literatura masiva, las marcas de la mundialización en las culturas nacionales". Revista Anàlisi, n. ${ }^{\circ}$ 43, 2011, pp. 73-87.

Paz, Octavio. En Testimonio y Literatura. Eds. Hernán Vidal y René Jara. Mineápolis, Society for the Study of Contemporary Hispanic and Lusophone Revolutionary Literatures, 1986.

Rama, Ángel. Transculturación narrativa en América Latina. México, Siglo xxi, 2004.

Rodríguez, Agustín. "Vivir sin causa: la cartografía de la devastación neoliberal". Ideas, Revista de Filosofía Moderna y Contemporánea, n. ${ }^{11}$, mayo de 2020-octubre de 2020, pp. 313-324.

Richard, Nelly. "Lo político en el arte: arte, política e instituciones". Revista Emisférica, 2018, s. p.

Valencia, Sayak. Capitalismo gore. España, Melusina, 2010.

Enviado: $1^{\circ}$ de diciembre de 2020

Aceptado: 20 de diciembre de 2020 